\title{
ethic \\ FROM THE NECESSITY OF BEING HUMAN TO THE POSSIBILITY OF PURSUING A GOOD LIFE: COGNITIVE ENHANCEMENT AND THE EMERGENCE OF PERSONHOOD
}

\author{
GIOVANA LOPES ${ }^{1}$ \\ (UNIVERSITÀ DI BOLOGNA/Italia) \\ BRUNELLO STANCIOLI ${ }^{2}$ \\ (UFMG/Brasil)
}

\begin{abstract}
Throughout human history, cognition enhancement has not only been a constant, but also imperative for our species evolution and well-being. However, philosophical assumptions that enhancing cognition by biomedical means goes against some immutable human nature, combined with the lack of conclusive data about its use on healthy individuals and long-term effects, can sometimes result in prohibitive approaches. In this context, the authors seek to demonstrate that cognition enhancement, whether by "natural" or biotechnological means, is essential to the emergence of personhood, and to existence of an autonomous life that is guided by a person's own conception of the good. In order to do so, the main possibilities of enhancing cognition through biotechnologies, along with its benefits and potentialities, as well as its risks and limitations, will be presented. Following Savulescu and Sandberg's account on cognitive enhancement, it will be argued that it constitutes both a consumption good, being desirable and happiness-promoting to have well-functioning cognition, and a capital good that reduces risks, increases earning capacity, and forms a key part of human capital. Finally, having in mind that progress in the field of biotechnology aimed at cognition enhancement may improve a person's (and society's) well-being, the authors will argue that further research in the field is necessary, especially studies that takes into consideration dimensions such as dose, individual characteristics and task characteristics.
\end{abstract}

Keywords: Human enhancement; Cognitive enhancement; Person; Personhood; Autonomy.

\section{Introduction}

In this paper it will be argued that cognitive enhancements play a vital role on the construction of personhood, and that future developments in the field may raise new possibilities for human beings to live autonomously according to their own conception of the good life. The main issue is that the lack of conclusive data about the use of biomedical cognitive 
enhancements on healthy individuals and long-term effects, combined with philosophical assumptions that they go against some immutable human nature, many times point to a prohibitive approach when it comes to regulation and further research.

Thus, the paper will begin by defining the terms relevant to human and cognitive enhancement, and by framing the relevant topics of the current debate on the theme. Next, the main possibilities of enhancing cognition through biotechnologies, along with its main risks and limitations, will be presented. Taking into consideration that cognition enhancement has been a constant throughout human history, Ingold's anthropological analysis of the role played by non-biomedical enhancements on human development (i.e. education) will be presented.

As theoretical framework, Floridi's "three-membrane model" of personal identity will be adopted since it highlights the importance of enhancement through the development of information processing systems. Then, it will be argued that enhancing cognitive capacities, whether through conventional or biotechnological means, is a necessary condition for the emergence of a person.

According to welfarists accounts of human enhancement, progress in the field of biotechnology aimed at cognition enhancement may improve a person's well-being. Therefore, arguments will be presented in favor of its research, regulation, and commercialization as such - instead of them entering the market as spin-offs of efforts to treat diseases or disorders.

The breadth of the theoretical bases on which the research is based implies, necessarily, its development from an interdisciplinary perspective that addresses philosophical, legal, neuroscientific, and social aspects of the problem. Methodologically speaking, the proposed research is essentially theoretical and bibliographic, drawing on direct and indirect sources for a comprehensive review of the theme.

\section{Enhancing cognitive capacities: framing the debate}

One must assume that human beings have always tried to enhance themselves by improving their mental and physical capacities (Clark 2003). As a matter of fact, Homo sapiens has been such a prolific species due to the great ability of relentlessly adapting to its environment, such as gaining control over fire and domesticating nature. It is not just the world around us that we desire to change, though: since the beginning of history humans have wanted to become more than just that, to become Homo superior, improving themselves in order to overcome their all-too-human limitations (Lin and Allhof 2008). 
Some practices aimed at enhancing human capabilities have been around for thousands of years, the prime example being education, which aims at improving general mental faculties such as concentration, memory, and critical thinking (Sandberg 2011). Other examples include meditation, the practice of sports, the adoption of an adequate diet and the use of food supplements.

Cognition enhancement, specifically, may be defined as the amplification or extension of core capacities of the mind - through augmentation or improvements of our information processing systems. In its turn, cognition can be defined as the processes that an organism uses to organize information. It includes, for example, acquiring information (perception), selecting (attention) and representing (understanding) information, as well as retaining it (memory). Interventions aimed at improving cognitive function may be directed at any of these core faculties of the mind (Sandberg 2011, 71).

On a very basic level, most people employ cognitive boosting strategies such as sleeping and exposing oneself to stimulating and complex environments. In addition, a lot of people also have personal experiences with cognitive enhancing substances such as caffeine, nicotine, and glucose, used to increase mental functioning (Fröding 2013). All of these may be labeled as conventional means of enhancing cognition, which are often well established and culturally accepted.

As cognitive neuroscience has advanced, enhancement by means of biotechnology aimed at improving cognitive function have steadily expanded (Farah et al. 2014). These biomedical enhancements, contrary to previous conventional techniques, use biotechnology to improve an existing capacity by acting directly on the body and brain of an individual (Buchanan 2011).

These include drugs, such as Ritalin and Modafinil, initially developed to treat TDHA and narcolepsy, but frequently used by students and professionals as means of improving focus and memory (Colzato and Mourits 2017; Colzato and Arntz 2017). Still new but receiving increasing interest are Apamine, NMDA agonists, GABAB blockers and CREB modulators (Fröding 2013), as well as microdosing psychedelics such as LSD to increase creativity and productivity (Prochazkova et al. 2018).

It also includes gene therapy, such as selecting which embryos to implant in the uterus by screening them for genes that are likely to result in better than normal capacities; and genetically engineering human embryos (fertilized egg cells) or gametes (sperm or egg cells) ${ }^{3}$. Besides, techniques of implanting genetically altered tissue into the body or brain and technologies that connect computers directly to the brain, such as 
transcranial magnetic stimulation (TMS) or transcranial direct current stimulation (tDCS), may also be regarded as cognitive enhancement (Buchanan 2011).

Enhancing cognition through these biotechnologies deserve serious consideration for several reasons: being relatively new, it does not exist, as consequence, a large body of "received wisdom" about their potential uses, safety, efficacy, or social consequences; and they could potentially have enormous leverage - especially when considering its cost-benefit ratio when compared to traditional means that require a lot of time and effort (Sandberg 2011).

Cognition is both a consumption good, being often desirable and happiness-promoting to have well-functioning cognition, and a capital good that reduces risks, increases earning capacity, and forms a key part of human capital (Savulescu and Sandberg 2011).

While low cognitive ability makes people vulnerable, hinders education and reduces the range of jobs which they can select, higher intelligence is likely correlated with lower accident rates, better health and longevity (Batty et al. 2007; Whalley and Deary 2001; Gottfredson 2007), reducing the losses from premature death, and generally preventing a wide array of social and economic misfortunes (Gottfredson 2004).

In the past couple of decades, a lot of research has been done in order to explore biological (and cultural) explanations for the frequent failure to respond rationally to information available to us (Fröding 2013). It has been shown that many people are challenged in their decision-making processes by biases, ungrounded fear, shortsightedness and misplaced epistemic deference (e.g. Greene and Haidt 2002; Kahneman 2011; Haidt 2001), and other similar constraints could have negative effects on overall level of wellbeing (e.g. Levy 2007; Singer 2005).

Human beings would be better able to solve pressing problems currently faced through an increase in creativity and intelligence. An enhancement that enables an individual to solve some of society's problems would produce a positive externality: in addition to benefits for the enhanced individual, there would be spillover benefits for other members of society (Sandberg 2011), something that makes them social rather than solely a personal good.

Besides, it is not too far reaching to say that biomedical enhancements will attract governments' interests, since they will care about the development and wide diffusion of those technologies that promise to increase productivity, and also reduce social (or rather, government) costs. In this context, Allen Buchanan (2011) points out to evidence that people on the low end of the normal distribution of intelligence tend to have more 
problems, such as alcoholism and drug abuse, that constitute a vast expense to states.

Today, the way in which a democratic society must deal with the forthcoming possibility of biomedical enhancements is still in dispute and appears to be highly controversial. In general, one can distinguish two main positions in this debate (Schermer 2012).

On the one side, there are (mainly) liberal authors who embrace a cognitive enhancement enterprise, and even argue for a moral duty of individuals to enhance themselves. Even though they do point to some obstacles that must first be overcame (e.g. safety or equal access), these authors usually focus on cognitive enhancement potential benefits, not only to individuals but also to society (as previously mentioned).

For example, in the field of moral philosophy, authors such as Bostrom (2005; 2009), Harris (2007), Savulescu (2009;2012), Buchanan (2011), Marchesini (2009), among others have pointed to the fact that improved cognitive function brings valuable non-positional benefits and should thus be pursued through biotechnologies.

On the other side of the debate, there are authors who take a more cautious and conservative position - and therefore are sometimes called "bioconservatives" -, arguing that the use of biomedical technologies for enhancing human capacities may lead to a decline of core human values like dignity (Kass 2002) and solidarity with weaker societal groups (Fukuyama 2003).

The problem of equality in fact rises on both ends of the debate. Given that contemporary globalized societies are based on competition, which underlies individual skills and performance, it is argued that cognitive enhancement might become a strictly positional good, by ameliorating one's social and economic status as compared to others (Colzato 2018), raising the issue of distributive justice.

However, some bioconservatives also fear that human beings with greatly enhanced capacities would threaten the equal moral status of the unenhanced. For Fukuyama (2002), human beings' equality rests on the fact that we all share the same human nature, which would be changed if we were to enhance ourselves in various ways. Therefore, any fundamental alterations to this shared nature would result on the fact that human beings would no longer be of equal moral status. However, as Wilson $(2007,421)$ explains, the "problem enhancement would create would be one of justice between those of equal moral status but unequal talents and capacities $(\ldots)^{\prime \prime}$.

It is worth noting that on many of these arguments the concept of "human nature" plays a central role, as it is often used as a reference state 
for the purpose of describing what is, and to justify moral arguments against an enhancement enterprise (Nielsen 2011).

For instance, appeals to human nature serve the point of representing what it means to be human, as in Habermas' (2003) appeal against the use of genetic enhancements because they would threat human nature: the ability of self-reflection and the autonomy to choose one's own life path. Also, the idea of human nature can feature as a feasibility constraint on morality, with authors like Sandel (2007) and Parens (2005) considering enhancement objectionable precisely for removing the limitations on what can be done by humans, since there are irreplaceable goods that depend upon our having limitations.

In general, the bioconservative speech conveys a normative essentialism grounded on the belief that it is possible to derive substantial moral rules from reflection on human nature, including a prohibition on human enhancement (Silva 2015).

As previously stated, "human enhancement" includes any activity by which humans improve their bodies, minds, or abilities - things one can do to enhance one's welfare. So, reading a book, eating vegetables, doing homework, and exercising may count as enhancing oneself (Lin and Allhof 2008). This so-called welfarist approach to enhancement may be defined as "any change in the biology or psychology of a person which increases the chances of leading a good life in the relevant set of circumstances" (Savulescu et al. 2011, 7).

Such definition of enhancement differs from those that seek to define it as opposed to therapy, i.e., any intervention aimed at correcting a specific pathology or defect that compromises the health or reduces the level of functioning in an individual below what is considered a normal level. This distinction between enhancement and therapy/medicine, however, is not often clear in practice, and has been pointed out by some authors as lacking practical significance (McKeown 2017; Bostrom and Roache, 2008; Daniels, 2000).

For example, cognition enhancement of somebody whose natural memory is poor could leave that person with a memory that is still worse than that of another one who has retained a fairly good memory despite suffering from an identifiable pathology, e.g., early-stage Alzheimer's disease. A cognitively enhanced person, therefore, is not necessarily somebody with particularly high or "superhuman" cognitive abilities, but rather somebody who has benefited from an intervention that improves the performance of some cognitive subsystem without correcting some specific, identifiable pathology or dysfunction of that subsystem (Sandberg 2011, 71). 
Besides, to a certain extent, therapy and enhancement are overlapping - all successful therapies are a kind of enhancement of impaired function, even if not all enhancements can be called therapeutic. It would be the case of improving and regenerating organs and tissues in the elderly, which could be an enhancement, but also be considered therapeutical as well (Ruud ter Meulen 2017).

Despite this, Buchanan $(2011,10)$ points out that in current discourse the term "enhancement" is usually attached only to interventions that involve biomedical technologies, something that is blinding to how pervasive enhancements are in everyday life and how central they have been to the origin and evolution of the human species.

This accounts for what the author have called "biomedical enhancement exceptionalism": the dogmatic assumption that because an enhancement involves biotechnologies, our ordinary moral tool kit is inadequate to deal with new kinds of issues that may arise due to its use. It also tempts us to assume without further reflection that there is something radically more problematic about biomedical enhancements than any other enhancement.

According to Harris $(2007,16)$, from "our first beginnings" there has been continuous efforts to improve our functioning - through education, language, health care, farming and others. All of these are means to improve the lives of human beings. For the author, this fact constitutes an argument in favor of the moral value of enhancement technologies:

If the goal of enhanced intelligence, increased powers and capacities, and better health is something that we might strive to produce through education, including of course the more general health education of the community, why should we not produce these goals, if we can do so safely through enhancement technologies or procedures? (...) Enhancements of course are good if and only if those things we call enhancements do good, and make us better, not perhaps by curing or ameliorating our ills, but because they make us better people (Harris 2007, 2).

Human beings, as opposed to other living beings, are the only ones to possess the potential to master their cognitive capabilities to an extent that goes beyond the element of natural chance (Ruud ter Meulen 2017) and to use this potential to improve their chances of increasing their wellbeing.

As highlighted by Naam (2005) far from being unnatural, the drive to alter and improve oneself is a fundamental part of humanity. As a species, 
human beings have always looked for ways to become stronger, smarter and to live longer. Many past enhancements that are frequently taken for granted today - from blood transfusions to vaccinations and birth control were regarded unnatural or immoral when they were first introduced. Yet over time people have become accustomed to these new levels of control over their minds and bodies, and have used them for the betterment of themselves, society, and the surrounding world.

In the past, increases in productivity, such as the ones aimed by cognitive enhancement, have been the platform for increases in human well-being. All the historical nonbiomedical enhancements - the agrarian revolution, literacy, computers, science - fit this pattern. Increased productivity does not ensure, by itself, increased well-being, but it creates the potential for it, by creating opportunities for more people to escape from unrewarding toil, to have more time for activities other than making a living, and by producing new goods and services while lowering costs (Buchanan 2011).

Simply put, the goal of cognitive enhancement, whether it be by conventional or biotechnological means, is to increase humans' well-being, allowing each person to live their life according to his or her own desires and conceptions of the good. As it will be demonstrated further along this work, this is something that not only has been a constant throughout human history, but that is also fundamental for the very own emergence of personhood.

Before that, however, it is first necessary to analyze what are the main biotechnologies that are currently being researched to improve cognition, and whether they have the potential to increase human beings' well-being.

\section{Cognitive enhancement by means of biotechnology}

As presented earlier, there are numerous approaches to cognitive enhancement, ranging from conventional methods to ones that use biotechnology to improve cognitive capacity by acting directly on an individual's body. Amongst these, focus now will be given to the most promising technologies currently available: cognition-enhancing drugs and noninvasive brain stimulation.

The use of drugs to enhance cognition is far from new; as Mehlman (2004) points out, the stimulant caffeine, for instance, has been widely used for this purpose for at least a thousand years. In this work, however, the term "drugs" will refer to nootropics i.e., pharmacological substances that have physiological effects on the brain (Fröding 2013). 
In recent years there has been an increase in media and web-based coverage of these drugs - also popularly known as "smart drugs" -, that is often uncritically enthusiastic about their benefits (Forlini and Racine 2009).

Methylphenidate (sold under the trade name Ritalin), mixed amphetamine salts (such as Adderall), and modafinil are three of the most purported drugs used for neuroenhancement among college students (Partridge et al. 2013; Ragan et al. 2013).

According to a survey conducted by Greely et al. (2008), 7\% of students in US universities had used prescription stimulants for improving their capacities for learning in the antecedent year - and on some campuses even up to $25 \%$. In Germany, a survey published by a health insurance company revealed that $5 \%$ of the employed persons in the country use pharmaceutical drugs for enhancing their cognitive performance (DAK 2009).

Drugs that are used to treat cognitive deficits in persons with clinical neuropsychiatric disorders alter neurotransmitter modulation of cognition and improve attention, learning, memory, and executive functions in these patients. The latter may be defined as mental processes that enable humans to plan, solve problems, and think flexibly about how to conduct complex everyday cognitive processes. Working memory, on its turn, is the ability to temporarily hold relevant information active over a short interval and to manipulate it online (Baddeley 2010).

These drugs improve cognition by balancing neurotransmitter systems (e.g., dopamine, noradrenaline) in ways that restore some aspects of cognition in these patients. In experimental settings, however, evidence from healthy volunteers shows that they improve robust neuropsychological cognitive tasks in both steep and inverted U-shaped fashion, with optimal enhancement dependent on taking the right dose and having the right baseline of cognitive function (de Jongh et al. 2008). Hence, because healthy individuals are using these drugs to amplify their cognitive capacities, they are now conceptualized as a form of cognitive enhancement (Mohamed 2017).

Donepezil (commercialized under the name Aricept) is an acetylcholinesterase inhibitor indicated for mild to moderate Alzheimer's disease (de Jongh 2017). Acetylcholinesterase inhibitors exert their effects by inhibiting the breakdown of acetylcholine, which increases the amount of acetylcholine in the synaptic cleft that can bind to muscarinic and nicotinic acetylcholine receptors (Mumenthaler et al. 2003).

In their review of studies on the effects of repeated administration of donepezil, Repantis et al. (2010a) state that donepezil administered for 6 weeks improved immediate and delayed word recall in elderly subjects 
(FitzGerald et al. 2008). In young participants, the drugs administered for 17 days had no effect on well rested subjects but reduced the decline in memory and attention that resulted from 24 hours of sleep deprivation (Chuah and Chee 2008; Chuah et al. 2009).

Besides, regarding effects of a single dose of donepezil, studies reveal that the drug improved information processing (Hutchison et al. 2001; Zaninotto et al. 2009), verbal episodic memory, spatial memory, working memory (Zaninotto et al. 2009), visuospatial working memory (Snyder et al. 2005), and procedural memory (Hornung et al. 2007). There were, however, null results reported on attention, working memory (Nathan et al. 2001), and declarative memory (Hornung et al. 2007).

Methylphenidate and mixed amphetamine salts are stimulants prescribed to treat attention deficit hyperactivity disorder (ADHD). They increase the synaptic concentrations of dopamine and norepinephrine by blocking their reuptake (de Jongh 2017). Amphetamine also increases catecholamine levels by increasing neurotransmitter release (Smith and Farah 2011).

After a review of 19 randomized controlled trials on the effects of methylphenidate, Repantis et al. (2010a) found positive effects of a single dose of methylphenidate only on memory (most prominently on spatial working memory), and no significant effects on attention, executive functioning, and mood.

Smith and Farah's (2011) review of 28 studies on the effects of psychostimulants, methylphenidate, and amphetamine found enhanced recall and recognition of verbal material, but only when subjects were tested after longer delays, from 1 hour up to 1 week (generally, no benefits were seen immediately following learning, which is when experimenters generally test memory for learned material). The finding that stimulants help with the consolidation of declarative memory, especially when longer periods intervene between learning and testing, is especially interesting for discussions on the ethical concern of fairness (de Jongh 2017).

For working memory and cognitive control the results were mixed, with some studies reporting enhancement and others null results. Effects were found to be the greatest for the least able participants (Smith and Farah 2011). Similarly, on a more recent study conducted by Ilieva et al. (2013) on the effects of mixed amphetamine salts, the researchers did not find enhancement of cognition for participants in general, but below-median baseline performers did improve on word recall and embedded figures, and there was a trend toward improved performance for these less able participants on a test of nonverbal intelligence. 
In short, the evidence is consistent with enhanced consolidation of long-term declarative memory, but effects on executive functioning (working memory and cognitive control), although they do appear on some tasks and for some individuals, are less reliable (de Jongh 2017).

Modafinil is an FDA approved, wake-promoting agent for the treatment of excessive daytime sleepiness associated with narcolepsy, obstructive sleep apnea/hypopnea syndrome, and "shift work sleep disorder." The mechanisms of its action are still unclear but are believed to be different from those of methylphenidate and amphetamine (Mohamed 2017). Effects on dopamine and norepinephrine presumably play an important role in its cognition-enhancing effects, although GABA, histamine, glutamate, and orexin/hypocretin may also be involved (Dresler et al. 2013; de Jongh et al. 2008).

Modafinil can sustain alertness and cognitive performance during prolonged periods of wakefulness (de Jongh et al. 2008). In addition, it can also enhance working memory, stopped signal reaction time, and improved spatial planning (Turner et al. 2003a), visual pattern recognition memory, speed of responding, and sustained attention (Randall et al. 2005a). Here again the drug was most effective in below-average performing subjects (Müller et al. 2004) and participants with a lower IQ (Randall et al. 2005b).

On their review of randomized controlled trials using modafinil, Repantis et al. (2010a) concluded that it had a positive (although moderate) effect on attention in subjects who were not sleep-deprived, while no effect could be detected on memory, mood, or motivation (and effects on executive functions could not be analyzed). In sleep deprived individuals, a single dose of modafinil had strong positive effects on executive functioning, memory, and wakefulness.

Müller et al. (2013) found that modafinil enhanced spatial working memory, planning, and decision-making at the most difficult levels of their cognitive tests in non-sleep-deprived participants. They also found an improved delayed visual pattern recognition memory and a large increase in task motivation.

On his review of experimental evidence of these cognition enhancing drugs, de Jongh $(2017,42)$ summarizes that

donepezil appears to enhance different types of memory, with both acute and repeated administration, although it is difficult to draw firm conclusions based on the small number of studies. The cognition-enhancing effects of methylphenidate are somewhat disappointing, being limited to memory, specifically spatial working memory, and perhaps enhanced 
recall and recognition of verbal materials at longer test intervals. For amphetamine, there is stronger evidence for the enhancement of the consolidation of declarative memory, especially when longer periods intervene between learning and testing. For both methylphenidate and amphetamine, evidence for enhancement of executive functions (working memory and cognitive control) is mixed, if not to say contradictory, with reports of enhancement, null results, and even impairment, depending on the task and the individual. And finally, with modafinil, a clear enhancing effect is found on attention in non-sleep deprived subjects, while in sleepdeprived participants, a single dose of modafinil had strong positive effects on executive functioning, memory, and wakefulness.

It is worth noting, however, that the use of these drugs for cognitive enhancement does not go without criticism. Besides pointing out to potential side-effects (Massie et al. 2017) and the very limited beneficial effects presented by them on healthy individuals, authors also question how they would translate into real world scenarios (Ilieva et al. 2013; Smith and Farah 2011).

Of special concern are critics regarding the potential of addiction of cognitive enhancement drugs (Heinz and Müller 2017). When it comes to modern addiction theories, the dopaminergic neurotransmitter systems play a key role: all known substances with addiction potential release dopamine in the reward systems, incentivizing further consumption (Di Chiara and Bassareo 2007; Everitt et al. 2008). Thus, developers of riskless cognitive enhancers face a dilemma: to do better than natural ways, one will have to interfere with systems that increase the risk of addiction (Heinz and Müller 2017).

Another relatively new technology that is being increasingly used to boost human cognition directly at the source by improving brain function is noninvasive brain stimulation (NBS). NBS techniques allow focal manipulation of brain function and have been advantageous for elucidating structure function relationships in the brain (Miniussi et al. 2013).

Besides, the ability to focally alter brain activity also allows for direct intervention with respect to neural function. This has led to the emergence of now accepted therapies (e.g., treatment for depression) as well as research investigations into promising clinical applications for both psychiatric and neurologic conditions. The ability to manipulate neural function noninvasively and focally, however, is also leading a growing 
number of investigators to explore the possibility of employing NBS to enhance normal human intellect (Shah-Basak and Hamilton 2017).

As opposed to invasive techniques that require surgical implantation of stimulation devices, such as deep brain stimulation, NBS allows for manipulation of brain function using components placed outside of the scalp.

Also, compared with pharmacological approaches to cognition enhancement, NBS present the advantage of stimulating specific neural structures that are associated with particular behaviors. By contrast, while drugs can selectively affect neurotransmitter systems, they generally do not manipulate the activity of circumscribed anatomical regions and can thus have effects on brain areas that are irrelevant to the cognitive operation in question. Besides, they frequently have systemic effects outside the brain as well (Shah-Basak and Hamilton 2017).

NBS can be classified into two types of technologies:

transcranial magnetic stimulation (TMS) and transcranial electrical stimulation (tES). These techniques differ in several important ways, both mechanistically in terms of their effects on brain function and methodologically with respect to their implementation. Within the category of tES (Paulus 2011), the most commonly employed method is transcranial direct current stimulation, although transcranial random noise stimulation (tRNS) and transcranial alternating current stimulation (tACS) have also recently emerged as promising methods for cognitive enhancement (Shah-Basak and Hamilton 2017, 126).

Several factors make tDCS a more attractive NBS approach than TMS for enhancing cognition, which is why this paper will focus on it. When compared to TMS, tDCS has fewer safety concerns: while the first is associated with a small but real risk of inducing seizures, the latter is safe and well tolerated by both healthy subjects and patient populations, and there are no reports of seizures or persistent adverse effects associated with it. Only mild side effects (e.g., tingling, itching, light burning sensations, and less frequently headaches) have been reported, but they do not last long past the period of stimulation (Brunoni et al. 2012; Kessler et al. 2012).

TMS is also an expensive method that can demand large auxiliary equipment and requires that subjects sit still during its application. On the other hand, tDCS is small and portable, and can be applied simultaneously 
with cognitive or behavioral tasks for associative training during stimulation, once that subjects are free to move their heads during it.

There is evidence that indicates that tDCS improves working memory performance (Fregni et al. 2005; Ohn et al. 2008; Zaehle et al. 2011), executive functions (Dockery et al. 2009b; Filmer et al. 2013; Chrysikou et al. 2013), cognitive-set-shifting performance (Leite et al. 2011; Karim et al. 2010), and language processing (Sparing et al. 2008; Fertonani et al. 2010; Cattaneo et al. 2011; Iyer et al. 2005) in healthy adults, among improvements in other cognitive capacities (for all, see Shah-Basak and Hamilton 2017).

It is worth noting that many studies in which tDCS has been used to boost aspects of cognition have been designed to elucidate structurefunction relationships in the brain. Therefore, they have employed limited numbers of stimulation sessions, and have only measured effects on behavior for brief periods following stimulation. However, there has been a surge in the number of studies that explore long-lasting effects of tDCS that suggest that sustained improvement in learning success was maintained over an extended period (Meinzer et al. 2014; Kadosh et al. 2010; Reis et al. 2009).

In light of these recent neuroscientific findings regarding the use of nootropic drugs and noninvasive brain stimulation in healthy subjects, although modest, it is not too far fetched to imagine a future scenario where they are also used as methods for enhancing some aspects of human cognition.

\section{Enhancement and the emergence of a person}

Transhumanism may be defined as an international movement to transform humanity by the development and use of enhancement technologies (Bostrom 2005). Proponents of this idea claim that human enhancement, instead of posing a threat to human dignity, will actually help increase it, since it will empower post-humans to overcome their vulnerabilities, to control the risks and uncertainties of their existence and to become independent of their natural surroundings (Bostrom 2005).

Post-humanists and enhancement supporters refuse to see the (existing) human body as something "given", but instead as "brute matter" which can be manipulated and altered (Edgar 2009) in order to achieve higher forms of existence and to live a more authentic life. As opposed to pre-modern conceptions of reality, according to which a static, given Nature existed as a mere object of contemplation, modern conceptions of reality 
view it as a process, a continuous flow of changes (Stancioli; Carvalho 2011).

In this context, the human body is no longer considered inviolable, being the abode of the soul, but it is regarded as part of reality, thus subjected to constant changes. Persons, then, have got an active role in this process of (re)constructing reality, being therefore agents of self.

Indeed, leaving aside any kind of mind-body dualism, it is clear that the construction of this self is intrinsically connected to an empirical substrate - not only the brain but the entire body of an individual. As Derek Parfit $(1984,216)$ puts it:

[A] person is distinct from his brain and body, and his experiences. But persons are not separately existing entities. The existence of a person, during any period, just consists in the existence of his brain and his body, and the thinking of his thoughts, and doing of his deeds, and the occurrence of many other physical and mental events.

Since personal experience is always mediated by this physical apparatus that is the body, it is now necessary to analyze how does the concept of person relates to it and to the very notion of human (and more precisely cognitive) enhancement.

According to philosopher's Mario Bunge theory of systems, if we have a system $\mathrm{s}$ then follows that:

$C(s)=$ Composition: Collection of all parts of s;

$E(s)=$ Environment: Collection of items, other than those in $s$ that act on or are acted upon some or all components of $s$; $\mathrm{S}(\mathrm{s})=$ Structure/Organization/Architecture: Collections of relations, in particular bonds, among components of $\mathrm{s}$ or among these and items in its environment $E(s)$;

$\mathrm{M}(\mathrm{s})=$ Mechanism (modus operandi): Collection of processes in $s$ that make it behave the way it does (Mario Bunge 2003, 46).

Following this, one could exemplify that the Solar System is composed by planets, the Sun, asteroids, etc.; its environment is the Universe; its structure is formed by the disposition and the interaction between the Sun and the planets, the movement of said planets, etc.; and that the mechanism according to which it is guided are the universal laws of physics.

Or one could state that the Internet is composed by PCs, laptops, wires, cellphones, and tablets; that its environment are houses, universities and human society in general; that it is structured by physical connections, 
FTP, e-mails, etc.; and that its mechanism is the exchange, (re)production and storage of information.

Still according to Bunge's theory (2003), one characteristic of complex systemic collections is emergence, according to which a set of things has a property (or properties) that are not had by any of its components individually, in a sense that can be said that a higher level of the system is produced.

Emergence, then, is a property of material systems and material things, and as such requires an explanation more than a mere description. It is the reason why there is qualitative novelty, or putting it simply, why new things, properties and processes arise from old, known objects (Bunge 2003). For example, think of the emergence of the Solar System, the Nation-State, or the human brain.

Personality too can be said to be an emergence property, as a person $\mathrm{p}$ has the following properties (or predicates):

$C(p)=$ Composition: a body (necessarily including the brain);

$E(p)=$ Environment: artifacts, information, language-as-action (Austin 1962; 1975);

$\mathrm{S}(\mathrm{p})=$ Structure: society (family, polis, State);

$M(p)=$ Mechanism/modus operandi: during direct and symbolic interactions with the environment, information is encapsulated by the brain, from which emerges an identity, a sense of self and a person.

According to this informational theory of personal identity, a person's unity - or self - emerges from a complex dynamic of both isolation and engagement with reality. This interaction constructs the person as a threephase system, in an explanatory model composed of what Floridi (2011, 558) called the three membranes model:

(...) selves emerge as the last step in a process of detachment from reality that begins with a corporeal membrane encapsulating an organism, proceeds through a cognitive membrane encapsulating an intelligent animal, and concludes with a consciousness membrane encapsulating a mental self or simply a mind. Of course, one may add as many mid-steps as required, yet these three-the corporeal, the cognitive and the consciousness (...)-seem to be the main stations at which the train of evolution has called. Each step builds on the previous one (supervenience) and, at each step, more nor less distance is placed between the entity and its environment. Each membrane is a defense of the structural integrity of what 
it encapsulates, against the surrounding environment. Of course, in moving from the corporeal, to the cognitive to the consciousness membrane, there is an increasing process of virtualization.

The three phases of the proposed model concern, then, the evolution of organisms into intelligent animals, and finally into self-conscious minds; and each phase contributes to the construction of the ultimate personal identity of the human organism in question.

In this sense, the body is the first individualizing element, being a person first and foremost an organism that results from the encapsulation of physical and biochemical elements. The corporeal membrane, then, defines a boundary between an individual's interior and the surrounding external world. Its primary function is to allow the exchange of primary data (e.g. lights, sounds, magnetic fields, chemical compounds) and protect the stability of the living system (physical homeostasis).

The evolutionary enhancement of complex biological structures more specifically, neurological structures - allows for the emergence of the second membrane that permeates reality: the cognitive system. It emerges from brain activity and promotes the encapsulation of data for processing and communication. Here, data such as gestures, visual patterns, and behaviors become encoded in primary language and memory.

Ingold's research demonstrates that speaking, writing, reading and performing actions that are loaded with meaning are skills that, like any other, are learned and developed from a continuous process of adaption and bodily adequacy, inside contexts of an individual's engaging with his surroundings. As the author explains,

the newborn infants cannot walk. They have to learn to walk, and the help of older persons, already competent in the art [...]. In short, walking is a skill that emerges for every individual in the course of a process of development, through the active involvement of an agent - the child - within the environment (Ingold 2011, 375).

Such learning depends, to a large extent, of the support from other persons that are already able to manage their own and body according to the needs of communication (Ingold 2011). But going even further, the acquisition of new skills causes continuous anatomical changes in an individual's brain (e.g. the alteration of his neural networks). Education (in a broader sense), thus, have physiological effects on one's brain, promoting the enhancing of not only cognitive, but also social abilities.

For example, 
the abilities both to speak, read and write emerge within a continuous process of bodily modification - involving a finetuning of vocal-auditory and manual-visual skills together with corresponding anatomical changes in the brain. Also, they take place within the context of the learner's engagement with other persons and diverse objects in his or her environment. In short, both capacities are properties of developmental systems (Ingold 2011, 377).

When evaluating what constitutes a person as a self in the modern identity context, autonomy is at the center of its contemporary conception, as a rational and eminently free subject able to choose ends, to formulate desires, to have interests and to eventually revise them and even abandon them. A person, then, can be described as an entity with autonomous rationality and an individual psychophysical profile in relation to others.

Being in relation to others reveals the essentially intersubjective character of the conception of a person established and affirmed only in relation to and dependent on others. As explained by Taylor $(1989,55)$, a self can only exist in relation to certain interlocutors: in one way, in relation to those conversation partners who were essential to one's achievement of self-definition; in another, in relation to those who are now crucial to the continuing grasp of languages of self-understanding. In short, the conception of a person necessarily involves some reference to a defining community or to "conversation networks", which is demonstrated by Ingold's analysis of the role played by cognition enhancement on human development.

Also, being a person encompasses the notion of individuality, that is, not only to assert oneself as a rational agent able to elect purposes and to have desires and beliefs but also to understand that there are differences from the purposes, desires and beliefs of others. The existence of an identity boundary between the self and the other is thus assumed, as a spatiotemporal extension represented by the body, and Floridi's informational model of the self represents.

These characteristics of a person also depend on a certain long-term stability - the personal identity of a subject, which is commonly defined in terms of reflexive self-consciousness and continuity of psychological states. As previously stated, because of the eminently relational character of the conception of a person, which depends on social interaction, it is not possible to state that personal identity is static; on the contrary, it is essentially changeable (including through the use of technology). 
In this sense, by referencing Taylor (1989), Elliott (2003) argues that some individuals use these technologies to make their existence more authentic. According to the author, authenticity means nowadays (at least in western cultures) that a person has to get in contact with her own inner nature, or inner voice, particularly when it threatens being lost because of external pressure to conform. It is, then, strongly linked to the idea of originality.

For Elliott (2003), this ideal of authenticity is driving the language of individuals using biotechnologies and other technologies to enhance their functioning. From the use of drugs to cosmetic medical interventions, using these technologies make people feel more authentic, or more like "being themselves".

In short, a person possesses a memory, consciousness, and is capable of transformation - provoking objective changes in the world, in one's own subjectivity, and in other persons. The way in which a person manipulates her brain, body (and values, consequently) implies, infinite forms of being. The main goal for human (and cognitive) enhancement, then, is to provide new possible forms of personhood, thus allowing everyone to live a life according to his or hers own desires and conception of the good life.

\section{A way forward: further developing cognitive enhancements}

Neuroenhancement advocates do not claim that today's techniques are optimal, but rather admit that they are not as efficient as desired. Although many of them recommend methylphenidate and/or modafinil for cognitive enhancement purposes, these drugs are not the cognitive enhancers they expect for the future and on which their positive judgments are based (Heinz; Muller 2017).

Several proponents of cognitive enhancement advocate for more research on the effectiveness and safety of neuroenhancement methods (Galert et al. 2009; Greely et al. 2008; Shaw 2012). This request is supported by the fact that knowledge about the positive and negative effects of these methods, especially drugs, is insufficient, at least regarding its nontherapeutic use by persons who consume them for the purpose of enhancement. This holds particularly for the addiction potential of today's and future neuroenhancers (Heinz; Muller 2017).

Most studies regarding the effects of neuroenhancers on healthy subjects have frequently been underpowered, with fewer than 40 participants in between-subject designs - which could explain the mix of positive and null results. Another explanation for null results reported in the literature is insufficient attention to individual differences, such as 
differences in baseline cognitive ability and COMT genotype of participants (Ilieva et al. 2013).

There is evidence suggesting that individual differences modulate the effects of cognitive enhancers, however this factor has generally been neglected in most studies (Smith and Farah 2011). Such investigations should report expectations relative to individual differences in baseline performance in the task, along with more general measures of intelligence; between subjects designs that overlook these differences are almost guaranteed to over or underestimate actual effects, inviting improper generalizations of the usefulness to people with different abilities (de Jongh 2017).

Some negative findings simply reflect ceiling effects: "in relatively high performing subjects without brain pathology or experimentally induced impairment it is difficult to improve cognitive performance with any given drug" (Müller et al. 2004). High-performing subjects, thus, might also benefit from neuroenhancers as long as the task is difficult enough to allow for an improvement of their performance (de Jongh 2017).

Another factor that frequently undermine investigations of this theme is the abundance of single-dose studies. Null results and detrimental effects of cognitive enhancers may result from a dose which is too low or too high, as some neuroenhancers, especially stimulants, seem to follow a U-shaped dose-response curve (de Jongh 2017). Smith and Farah (2011) point out that the optimal dose depends on individual characteristics and the task at hand, and therefore cannot be easily predicted on the basis of data from previous experiments.

Summarizing the problem, the authors state that

Optimizing the cognitive effects of a stimulant would therefore require, in effect, a search through a high dimensional space whose dimensions are dose; individual characteristics such as genetic, personality, and ability levels; and task characteristics. The mixed results in the current literature may be due to the lack of systematic optimization (Smith and Farah 2011, 19).

Moreover, stimulants may be more helpful than laboratory tasks indicate, since subjects in the lab are usually tested soon after learning, but the enhancing effects of amphetamines on episodic memory were only detected when longer retention intervals were used (Smith and Farah 2011). It is precisely this long-term effect on learning, however, that is of practical value (de Jongh 2017). 
Ilieva et al. (2013) also point that effects might be larger in real-world scenarios, where tasks take longer (and thus become more tedious) and when there are more distractions present than in laboratory settings. According to the authors, mixed amphetamine salts might have a larger effect on motivation to work, something that plays a bigger role in everyday life than in the lab. Effects on motivation have been found by Volkow et al (2004) and Müller et al. (2013).

Another reason why benefits in real-world scenarios may be underestimated is that while most studies focus on non-sleep-deprived, well-rested healthy subjects, effects of cognitive enhancers are much more pronounced in subjects that are in fact sleep deprived - and, although healthy, a lot of people are far from adequately rested (de Jongh 2017).

Further support for the viewpoint that neuroenhancers may be more helpful in real life than in laboratory tasks can be found when analyzing the effects of caffeine. Under laboratory conditions, its effects appear to be small and often contradictory, as is the case of cognitive enhancers mentioned in this paper. However, looking at the effects of caffeine in the workplace, there is evidence that it is associated with half the risk of cognitive failures and accidents at work (de Jongh 2017). For the enhancing techniques mentioned in this paper, studies in the workplace or at least approximating real-world scenarios are scarce.

In sum, there is clearly a need for further research regarding neuroenhancers, especially taking into consideration the limitations previously pointed. Two different research strategies could help provide answers: double-blind, randomized long-term studies with healthy volunteers; and epidemiological studies (Heinz and Müller 2017).

Regarding the first strategy, clinical studies that investigate the efficacy and adverse effects, particularly de novo addictions, could be performed with young volunteers, who would be randomly assigned to different groups (e.g. different drugs, dosage, placebo). Research protocol would demand that subjects do not take other drugs during the study, and persons with mental disorders, known risk factors for mental disorders, psychiatric history or problematic drug consumption would be excluded for scientific and ethical reasons (Heinz and Müller 2017).

Clinical studies need the approval of ethics commissions to be carried out, and thus they must fulfill some minimal criteria, such as investigating a reasonable goal, obtaining informed consent from participants, and having an acceptable risk-benefit profile. Regarding the latter, Heinz and Müller (2017) point to the fact that investigating the addictive effects of cognitive enhancers could be rather tricky, as larger groups of previously healthy individuals would have to be exposed to a potentially addictive drug. 
For the authors, since healthy volunteers could not expect any relevant benefits from study participation (except payment), the riskbenefit ratio for exposures would be rather unfavorable. However, some consideration should also be given to the possible benefits for society.

Epidemiological studies, on the other, could collect information about the benefits and risks of drugs used for cognitive enhancement, with the advantage of providing a realistic picture of current patterns of use and including people who are more representative of the whole society. Also, the analysis of demographic data together with data on the consumption of prescription psychotropic drugs, recreational drugs, medications etc. could reveal risk factors for adverse effects of cognitive enhancers (including addiction). Their main disadvantage, however, would be the heterogeneity of the subjects, which thus requires a large number of subjects, and the fact that epidemiological studies can rarely produce conclusive evidence of causal relationships (Heinz and Müller 2017).

\section{Concluding remarks}

Interestingly, both the optimistic and the cautions positions regarding neuroenhancements often do not refer to empirical evidence about the impact of such technologies. On the one side, cognition enhancement supporters are not very interested in the question of its effectiveness and possible harmful side effects. On the other side, bioconservatives frequently paint gloomy scenarios that are not based on empirical data about the impact of cognitive enhancement technologies on society. Although empirical data cannot decide by itself the outcome of moral debates, it is important that consideration on what neuroenhancement technologies can accomplish is taken.

Thus, this paper sought to present the main possibilities of enhancing cognition through biotechnologies, along with its benefits and potentialities, as well as its risks and limitations. As previously seen, the lack of conclusive data on the use of neuroenhancers by healthy subjects should not simply result on a ban of these methods, but rather on incentives for further research and development - especially taking into consideration the potential benefits for individuals and society.

Cognitive enhancement brings valuable non-positional benefits. Cognition is both a consumption good, being often desirable and happinesspromoting to have well-functioning cognition, and also a capital good that reduces risks, increases earning capacity, and forms a key part of human capital. 
Cognition enhancement has been a constant throughout human history, playing an essential role in the evolution of our species and in the construction of personhood, thus allowing human beings to live autonomously according to their own conception of the good life. Philosophical assumptions stating that enhancing cognition by biomedical means goes against some immutable human nature are, therefore, unfounded. A prohibitive approach based on such arguments, then, cannot be sustained.

Having in mind that progress in the field of biotechnology aimed at cognition enhancement may improve a person's well-being, according to welfarists accounts of human enhancement, further research in the field that takes into consideration subject's individual characteristics, task characteristics, translation into real-life scenarios, ceiling effects, U-shaped dose-response curves, and long-term effects. 


\section{Notes}

${ }^{1}$ PhD candidate in Law, Science and Technology at the University of Bologna (Italy) and KU Leuven (Belgium); ORCID-iD: https://orcid.org/0000-0003-4798-2542; email: giovanaplopes@gmail.com

2 PhD from the Federal University of Minas Gerais (UFMG), with a postdoctoral degree from the University of Oxford (Center for Practical Ethics at Uehiro). Associate professor of undergraduate and graduate law programs at the Federal University of Minas Gerais. ORCID-iD: https://orcid.org/0000-0001-7795-0395; email: brunellostancioli@gmail.com

${ }^{3}$ It is important to note that these are, at present, merely speculative means for enhancing human cognition, and further research is still necessary regarding its future use and ethical challenges. 


\section{References}

Baddeley, Alan. 2010. "Working memory". Current Biology 20(4): 136-40.

Batty, G David, Ian Deary and Linda Gottfredson. 2007. "Premorbid (early life) IQ and later mortality risk: Systematic review". Annals of Epidemiology 17(4): 278-88.

Bell, Stephanie, Brad Partridge, Jayne Lucke and Wayne Hall. 2013. "Australian University students' attitudes towards the acceptability and regulation of pharmaceuticals to improve academic performance". Neuroethics 6(1): 197-205.

Bostrom, Nick. 2005. "In Defense of Posthuman Dignity". Bioethics 19(3): 202-14.

Bostrom, Nick. 2009. "The Wisdom of Nature: An evolutionary heuristic for human enhancement". In Human Enhancement, edited by Julian Savulescu and Nick Bostrom, 375-416. Oxford: Oxford University Press.

Bostrom, Nick and Rebecca Roache. 2011. "Smart Policy: Cognitive Enhancement and the Public Interest". In Enhancing Human Capacities, edited by Julian Savulescu, Ruud ter Meulen and Guy Kahane, 137-149. New Jersey: Wiley-Blackwell.

Brunoni, Andre, Roberta Ferrucci, Felipe Fregni, Paulo Boggio and Alberto Prioli. 2012. "Transcranial direct current stimulation for the treatment of major depressive disorder: a summary of preclinical, clinical and translational findings". Progress in Neuropsychopharmacology and Biological Psychiatry 39(1): 9-16.

Buchanan, Allen. 2011. Better than Human: The promise and perils of enhancing ourselves. Oxford: Oxford University Press.

Buchanan, Allen. 2011. Beyond Humanity? The Ethics of Biomedical Enhancement. Oxford: Oxford University Press.

Bunge, Mario. 2003. Emergence and Convergence: Qualitative Novelty and the Unity of Knowledge. Toronto: University of Toronto Press.

Cattaneo, Zaira, A Pisoni and C Papagno. 2011. "Transcranial direct current stimulation over Broca's region improves phonemic and semantic fluency in healthy individuals". Neuroscience 223:56-67. 
Chrysikou, Evangelia, Roy Hamilton, H Branch Coslett, Abhishek Datta Marom Bikson and Sharon Thompson-Schill. 2013. "Noninvasive transcranial direct current stimulation over the left prefrontal cortex facilitates cognitive flexibility in tool use". Cognitive Neuroscience 4(2): 819.

Chuah, Lisa, Delise Chong, and William Rekshan. 2008. "Cholinergic augmentation modulates visual task performance in sleep-deprived young adults". Journal of Neuroscience 28: 11369-77.

Chuah, Lisa, Delise Chong, Annette Chen, William Rekshan, Jiat-Chow Tan, Hui Zheng, Michael Chee. 2009. "Donepezil improves episodic memory in young individuals vulnerable to the effects of sleep deprivation". Sleep 32(8): 999-1010.

Clark, Andy. 2003. Natural-born Cyborgs: Minds, technologies, and the future of human intelligence. Oxford: Oxford University Press.

Cohen Kadosh, Roi, Sonja Soskic, Teresa Iuculano, Royota Kanai and Vincent Walsh. 2010. "Modulating neuronal activity produces specific and long-lasting changes in numerical competence". Current Biology 20(22): 2016-20.

Colzato, Lorenza and Fréderique Arntz. 2017. "Ritalin". In Theory-driven approaches to cognitive enhancement, edited by Lorenza Colzato, 71-82. New York: Springer.

Colzato, Lorenza and Rebecca Mourits. 2017. "Modafinil". In Theory-driven approaches to cognitive enhancement, edited by Lorenza Colzato, 83-94. New York: Springer.

Colzato, Lorenza. 2018. "Responsible Cognitive Enhancement". Journal of Cognitive Enhancement 2(4): 331-4.

Dak. 2009. Gesundheitsreport 2009: Analyse der Arbeitsunfähigkeitsdaten. Schwerpunktthema Doping am Arbeitsplatz. Hamburg: DAK Forschung.

Daniels, Norman. 2000. "Normal Functioning and the TreatmentEnhancement Distinction". Cambridge Quarterly of Healthcare Ethics 9(3): 309-22.

Dockery, Colleen, Ruth Hueckel-Weng, Niels Birbaumer and Christian Plewnia. 2009. "Enhancement of planning ability by transcranial direct current stimulation". Journal of Neuroscience 29(22): 7271-77. 
Dresler, Martin, Sandberg, Anders, Kathrin Ohla, Christoph Bublitz, Carlos Trenado, Aleksandra Mroczko-Wasowicz, Simone Kühn and Dimitris Repantis. 2013. "Non-pharmacological cognitive enhancement", Neuropharmacology 64: 529-43.

Edgar, Andrew. 2009. "The hermeneutic challenge of genetic engineering" Medicine, Health Care and Philosophy 12(2):157-67.

Elliott, Carl. 2003. Better than well: American medicine meets the American dream. New York: Norton and Company.

Everitt, Barry, David Belin, Daina Economidou, Yann Pelloux, Jeffrey Dalley and Trevor Robbins. 2008. "Neural mechanisms underlying the vulnerability to develop compulsive drug-seeking habits and addiction", Philososophical Transactions of the Royal Society of London 363(1507): 3125-35.

Farah, Martha, Judy Illes, Robert Cook-Deegan, Howard Gardner, Eric Kandel, Patricia King, Eric Parens, Barbara Sahakian et al. 2004. "Neurocognitive enhancement: What can we do and what should we do?" Nature Reviews Neuroscience 5(5): 421-5.

Farah, Martha, M Elizabeth Smith, Irena Ilieva and Roy Hamilton. 2014. "Cognitive Enhancement". Wiley Interdisciplinary Reviews: Cognitive Science 5(1): 95-103.

Fertonani, Anna, Sandra Rosini, Maria Cotelli, Paolo Rossini and Carlo Miniussi. 2010. "Naming facilitation induced by transcranial direct current stimulation". Behavioural Brain Research 208(2): 311-8.

Filmer, Hannah, Jason Mattingley, and Paul E Dux. 2013. "Improved multitasking following prefrontal tDCS". Cortex 49(1), pp. 2845-52.

FitzGerald, David, Gregory Crucian, Jeannine Mielke, Brian Shenal, David Burks, Kyle Womack, Georges Ghacibeh, Valeria Drago, Paul Foster, Edward Valenstein et al. 2008. "Effects of donepezil on verbal memory after semantic processing in healthy older adults". Cognitive and Behavioral Neurology 21(2):57-64.

Floridi, Luciano. 2011. "The informational nature of personal identity". Minds and Machines 21: 549-66.

Forlini, Cynthia and Eric Racine. 2009. "Disagreements with implications: diverging discourses on the ethics of non-medical use of methylphenidate for performance enhancement". BMC Medical Ethics 10(9). 
Fregni, Felipe, Paulo Boggio, Michael Nitsche, Felix Bermpohl, Andrea Antal, Eva Feredoes, Marco Marcolin, Sergio Rigonatti, Maria Silva, Walter Paulus et al. 2005. "Anodal transcranial direct current stimulation of prefrontal cortex enhances working memory". Experimental Brain Research 166(1): 23-30.

Fröding, Barbro. 2013. Virtue Ethics and Human Enhancement. New York: Springer.

Fukuyama, Francis. 2002. Our Posthuman Future: Consequences of the biotechnology revolution. New York: Farrar Straus Giroux.

Gottfredson, Linda. 2004. "Life, Death, and Intelligence". Journal of Cognitive Education and Psychology 4(1): 23-46.

Gottfredson, Linda .2007. "Innovation, Fatal Accidents, and the Evolution of General Intelligence". In Integrating the Mind: Domain general versus domain specific processes in higher cognition, edited by Maxwell Roberts, 387-425. Hove: Psychology Press.

Greely, Henry, Barbara Sahakian, John Harris, Ronald Kessler, Michael Gazzaniga, Philip Campbell and Martha Farah. 2008. "Towards responsible use of cognitive-enhancing drugs by the healthy". Nature 456: 702-5.

Greene, Joshua and Jonathan Haidt. 2002. "How (and Where) does Moral Judgment Work?". Trends in Cognite Science (12): 517-23.

Haidt, Jonathan. 2001. "The Emotional Dog and its Rational Tail: A social intuitionist approach to moral judgment". Psychology Review 108(4): 81434.

Harris, John. 2007. Enhancing Evolution: The ethical case for making better people. Princeton: Princeton University Press.

Heinz, Aandreas and Sabine Müller. 2017. "Exaggerating the benefits and downplaying the risks in the bioethical debate on cognitive neuroenhancement". In Rethinking Cognitive Enhancement, edited by Ruud Ter Meulen, Ahmed Mohamed and Wayne Hall, 69-86. Oxford: Oxford University Press.

Hornung, Orla, Francesca Regen, Heidi Danker-Hopfe, Michael Schredl and Isabella Heuser. 2007. "The relationship between REM sleep and memory consolidation in old age and effects of cholinergic medication". Biological Psychiatry 61(6): 750-7. 
Hutchison, C W; P J Nathan, L Mrazek and C Stough. 2001. "Cholinergic modulation of speed of early information processing: the effect of donepezil on inspection time". Psychopharmacology 155: 440-2.

Ilieva, Irena, Joseph Boland and Martha Farah. 2013. "Objective and subjective cognitive enhancing effects of mixed amphetamine salts in healthy people". Neuropharmacology 64: 496-505.

Ingold, Tim. 2011. The Perception of the Environment: Essays on livelihood, dwelling and skill. London: Routledge.

Iyer, M B, U Mattu, J Grafman et al. 2005. "Safety and cognitive effect of frontal DC brain polarization in healthy individuals". Neurology 64(5): 8725.

de Jongh, Reinoud, Ineke Bolt, Maartje Schermer, and Berend Olivier. 2008. "Botox for the brain: Enhancement of cognition, mood and pro-social behavior and blunting of unwanted memories". Neuroscience and Biobehavioral Reviews 32(4): 760-76.

De Jongh, Reinoud. 2017. "Overclocking the brain? The potential and limitations of cognition-enhancing drugs" In Rethinking Cognitive Enhancement, edited by Ruud Ter Meulen, Ahmed Mohamed and Wayne Hall, 37-56. Oxford: Oxford University Press.

Kahneman, Daniel. 2011. Thinking, Fast and Slow. New York: Farrar, Straus and Giroux.

Kessler, Sudha, Peter Turkeltaub, Jennifer Benson and Roy Hamilton. 2012. "Differences in the experience of active and sham transcranial direct current stimulation". Brain Stimulation 5(2): 155-62.

Karim, Ahmed, Markus Schneider, Martin Lotze, Ralf Veit, Paul Sauseng, Christoph Braun and Niels Birbaumer. 2010. "The truth about lying: inhibition of the anterior prefrontal cortex improves deceptive behavior". Cerebral Cortex 20(1): 205-13.

Kass, Leon. 2000. "The Wisdom of Repugnance". In The Human Cloning Debate, edited by Glenn MacGee, 68-106. Berkeley: Berkeley Hills Books.

Leite, Jorge, Sandra Carvalho, Felipe Fregni, and Oscar Goncalves. 2011. "Task-specific effects of tDCS-induced cortical excitability changes on cognitive and motor sequence set shifting performance". PLOS One 6(9): e24140. 
Levy, Neil. 2007. Neuroethics: Challenges for the 21st century. Cambridge: Cambridge University Press.

Lin, Patrick and Francis Allhoff. 2008. "Untangling the Debate: The Ethics of Human Enhancement". Nanoethics 2(3): 251-64.

De Luca, Maria Antonietta, Valentina Bassareo, A Bauer and Gaetano Di Chiara. 2007. "Caffeine and accumbens shell dopamine". Journal of Neurochemistry 103(1): 157-63.

Marchesini, Roberto. 2009. Il Tramonto dell'Uomo: La prospettiva postumanista. Bari: Edizione Dedalo.

Massi, Charles, Eric Yamga and Brendon Boot. 2017. "Neuroenhancement: a call for better evidence on safety and efficacy" In Rethinking Cognitive Enhancement, edited by Ruud Ter Meulen, Ahmed Mohamed A and Wayne Hall, 57-68. Oxford: Oxford University Press.

McKeown, Alex. 2017. "Enhancement and Therapy: Is it possible to draw a line?" In Rethinking Cognitive Enhancement, edited by Ruud ter Meulen, Ahmed Mohamed and Wayne Hall. Oxford: Oxford University Press.

Mehlman, Maxwell. 2004. "Cognition-enhancing drugs". Milbank Quarterly 82(3): 483-506.

Meinzer, Marcus, Sophia Jahnigen, David Copland, Robert Darkow, Ulrike Grittner, Keren Avirame, Amy Rodriguez, Robert Lindenberg and Agnes Floel. 2014. "Transcranial direct current stimulation over multiple days improves learning and maintenance of a novel vocabulary". Cortex 50: 13747.

Miniussi, Carlo, Justin Harris and Manuela Ruzzoli. 2013. "Modelling noninvasive brain stimulation in cognitive neuroscience". Neuroscience and Biobehavioral Reviews 37(8): 1702-12.

Mohamed, Ahmed. 2017. "Does modafinil improve cognitive functioning in healthy individuals?" In Rethinking Cognitive Enhancement, edited by Ruud Ter Meulen, Ahmed Mohamed and Wayne Hall, 107-24. Oxford: Oxford University Press.

Mohamed, Ahmed. 2017. "Does modafinil improve cognitive functioning in healthy individuals?" In Rethinking Cognitive Enhancement, edited by Ruud Ter Meulen, Ahmed Mohamed and Wayne Hall, 87-106. Oxford: Oxford University Press. 
Müller, Ulrich, Nikolai Steffenhagen, Ralf Regenthal and Peter Bublak. 2004. "Effects of modafinil on working memory processes in humans". Psychopharmacology 177(1): 161-9.

Müller, Ulf, Jurgen Voges, Johann Steiner, Imke Galazky, Hans-Jochen Heinze, Michaela Möller, Jared Pisapia, Casey Halpern, Arthur Caplan, Bernard Bogerts et al. 2013. "Deep brain stimulation of the nucleus accumbens for the treatment of addiction". Annals of the New York Academy of Sciences 1282: 119-28.

Mumenthaler, Martin, Jerome Yesavage, Joy Taylor, Ruth O'Hara, Leah Friedman, Hana Lee and Helena Kraemer. 2003. "Psychoactive drugs and pilot performance: a comparison of nicotine, donepezil, and alcohol effects". Neuropsychopharmacology 28: 1366-73.

Naam, Ramez. 2005). More than human: embracing the promise of biological enhancement. New York: Random House Broadway Books.

Nathan, Pradeep, Allison Baker, Elaine Carr, Jemima Earle, Maeghan Jones, Michelle Nieciecki, Chris Hutchison and Con Stough. 2001. "Cholinergic modulation of cognitive function in healthy subjects: acute effects of donepezil, a cholinesterase inhibitor". Human Psychopharmacology 16(6): $481-3$.

Nielsen, Lisbeth. 2011. "The Concept of Nature and the Enhancement Technologies Debate". In Enhancing Human Capacities, edited by Julian Savulescu, Ruud ter Meulen and Guy, 19-33.New Jersey: Wiley- Blackwell.

Ohn, Suk, Chang-Il Park, Woo-Kyoung Yoo, Myoung-Hwan Ko, Kyung Choi, Gyeong-Moon Kim, Yong Lee and Yun-Hee Kim. 2008. "Time-dependent effect of transcranial direct current stimulation on the enhancement of working memory". Neuroreport 19(1): 43-7.

Parens, Eric. 1998. Enhancing Human Traits: Ethical and social implications. Washington: Georgetown University Press.

Parfit, Derek. 1984. Reasons and Persons. Oxford: Oxford University Publishing.

Prochazkova Luisa, Dominique Lippelt, Lorenza Colzato, Martin Kuchar, Zsuzsika Sjoerds and Bernhard Hommel. 2018. "Exploring the effect of microdosing psychedelics on creativity in an open-label natural setting". Psychopharmacology 235(12): 3401-13. 
Ragan, Ian, Imre Bard and Illina Singh. 2013. "What should we do about student use of cognitive enhancers? An analysis of current evidence". Neuropharmacology 64: 588-95.

Randall, Delia, Fay Cafferty, John Shneerson, Ian Smith, Meirion Llewelyn and Sandra File. 2005. "Chronic treatment with modafinil may not be beneficial in patients with chronic fatigue syndrome". Journal of Psychopharmacology 19(6): 647-60.

Reis, Janine, Heidi Schambra, Leonardo Cohen, Ethan Buch, rita Fitsch, Eric Zarahn, Pablo Celnik and John Krakauer. 2009. "Noninvasive cortical stimulation enhances motor skill acquisition over multiple days through an effect on consolidation". Proceedings of the National Academy of Science USA 106(5): 1590-5.

Repantis, Dimitris, Oona Laisney and Isabella Heuser. 2010. "Acetylcholinesterase inhibitors and memantine for neuroenhancement in healthy individuals: a systematic review". Pharmacological Research 61(6): 473-81.

Ruud ter Meulen. 2017. "The ethical debate on human enhancement and cognitive enhancement by way of biotechnologies". In Rethinking Cognitive Enhancement, edited by Ruud ter Meulen, Ahmed Mohamed and Wayne Hall, 15-34. Oxford: Oxford University Press.

Sandberg, Andy. 2011. "Cognition Enhancement: Upgrading the Brain". In Enhancing Human Capacities, edited by Julian Savulescu, Ruud ter Meulen and Guy Kahane, 71-91. New Jersey: Wiley-Blackwell.

Sandberg, Andy and Julian Savulescu. 2011. "The Social and Economic Impacts of Cognitive Enhancement". In Enhancing Human Capacities, edited by Julian Savulescu, Ruud ter Meulen and Guy Kahane, 92-112. New Jersey: Wiley-Blackwell.

Sandel, Michael. 2007. The case against perfection. Cambridge: Harvard University Press.

Savulescu, Julian and Ingmar Persson. 2012. Unfit for the Future: The Need for Moral Enhancement. Oxford: Oxford University Press.

Savulescu, Julian and Nick Bostrom. 2009. Human Enhancement. Oxford: Oxford University Press.

Schermer, Maartje. 2012. Van genezen naar verbeteren. Inaugural lecture. Rotterdam: Erasmus Medical Centre. 
Shah-Basak, Priyanka and Roy Hamilton. 2017. "Cognitive enhancement using noninvasive brain stimulation: weighing opportunity, feasibility, and risk". In Rethinking Cognitive Enhancement, edited by Ruud Ter Meulen, Ahmed Mohamed and Wayne Hall, 125-49. Oxford: Oxford University Press.

Singer, Peter. 2005. "Ethics and Intuition". The Journal of Ethics 9(3): 33152.

Silva, Denis. 2015. "Posthumanism and Equality". In: Human Rights, Rule of Law and the Contemporary Social Challenges in Complex Societies: Proceedings of the XXVI World Congress of Philosophy of Law and Social Philosophy of the Internationale Vereinigunf für Rechtsund Sozialphilosophie, edited by Marcelo Galuppo, Mônica Lopes, Lucas Gontijo, Karine Salgado and Thomas Bustamente, 1942-54. Belo Horizonte: Initia Via.

Smith, Elizabeth and Martha. 2011. "Are prescription stimulants "smart pills"? The epidemiology and cognitive neuroscience of prescription stimulant use by normal healthy individuals". Psychological Bulletin 137(5): 717-41.

Snyder, Peter, Martin Bednar, Jennifer Cromer and Paul. 2005. "Reversal of scopolamine-induced deficits with a single dose of donepezil, an acetylcholinesterase inhibitor". Alzheimers and Dementia 1(1): 126-35.

Sparing, Roland, Manuel Dafotakis, Ingo Meister, Nivethida Thirugnanasambandam and Gereon Fink. 2008. "Enhancing language performance with non-invasive brain stimulation: a transcranial direct current stimulation study in healthy humans". Neuropsychologia 46(1): 261-8.

Stancioli, Brunello and Nara Carvalho. 2011. "Da Integridade Física ao Livre Uso do Corpo" In: Manual de Teoria Geral do Direito Civil, edited by Ana Carolina Brochado and Gustavo Leite, 265-85. Belo Horizonte: Del Rey.

Taylor, Charles. 1989. Sources of the Self: The making of modern the modern identity. Cambridge: Harvard University Press.

Turner, Danielle, Trevor Robbins, Luke Clark, Adam Aron, Jonathan Dowson and Barbara Sahakian .2003. "Cognitive enhancing effects of modafinil in healthy volunteers". Psychopharmacology 165(3): 260-9.

Volkow, Nora, Gene-Jack Wang, Joanna Fowler, Telang Frank, Laurence Maynard, Jean Logan, Samuel Gatley et al. 2004. "Evidence that methylphenidate enhances the saliency of a mathematical task by increasing dopamine in the human brain". American Journal of Psychiatry 161(7): 1173-80. 
Whalley, Lawrence and Ian Deary. 2001. "Longitudinal Cohort Study of Childhood IQ and Survival up to Age 76". British Medical Journal 322(7290): 819-22.

Wilson, James. 2007. "Transhumanism and Moral Equality". Bioethics 21(8): 419-25.

Zaehle, Tino, Pascale Sandmann, Jeremy Thorne, Lutz Jäncke and Christoph Hermann. 2011. "Transcranial direct current stimulation of the prefrontal cortex modulates working memory performance: combined behavioural and electrophysiological evidence". BMC Neuroscience 12(2).

Zaninotto, Ana, Orlando Bueno, Márcia Pradella-Hallinan, Sérgio Tufik, Jenny Rusted, Con Stough and Sérgio Pompéia. 2009. "Acute cognitive effects of donepezil in young, healthy volunteers". Human Psychopharmacology 24(6): 453-64. 